\title{
Pengaruh Metode 5'S (Swadding, Stomach Position, Sushing, Swingging, Sucking) terhadap Respon Nyeri Bayi Setelah Imunisasi HB-0
}

\author{
Syatriawati $1^{1,}$, Iskandar Markus Sembiring ${ }^{2}$ \\ 'Fakultas Keperawatan, Institut Kesehatan Medistra Lubuk Pakam, Lubuk Pakam, 20512, Indonesia \\ ${ }^{2}$ Fakultas Keperawatan, Institut Kesehatan Medistra Lubuk Pakam, Lubuk Pakam, 20512, Indonesia \\ ${ }^{1}$ Email : atria.suhaimi@yahoo.co.id ${ }^{*} ;{ }^{2}$ Email : iskandar_sembiring@ymail.com; \\ * corresponding author
}

Keywords

Baby

The 5's method

Pain
Immunization is a source of acute pain in infants that can cause trauma, nonpharmacological techniques that can be done is by giving of 5'S method (swaddling, stomach position, sushing, swinging, and sucking) which are effective and easy to do and the purpose of this study was to find out whether there is an effect of 5'S method (swaddling, stomach position, sushing, swinging and sucking) on pain response in infants after Hb-0 immunization at Grandmed Hospital Lubuk Pakam, the method and design of this study was Quasy Experiment with one group pre test and post test design. the population in this study were infants aged0-7 days who received $\mathrm{Hb}-0$ immunization, amounting to 40 people with purposive sampling technique according to inclusion criteria and pain measurement uses the NIPS (Neonatal Infant Pain Scale) pain scale, the data analysis was performed by Paired Sample t-test with a confidence level of $0.05 \%$, the results of the study were lower pain in the treatment group with $\mathrm{p}=$ $0.0000<0.05(<a)$, the conclusion of this study is that there was an effect of the 5'S method (swaddling, stomach position, sushing, swinging, and sucking) on pain response in infants after $\mathrm{Hb}-0$ immunization.

\section{Pendahuluan}

Usia neonatus (periode bayi) merupakan fase yang sangat penting bagi tumbuh kembang serta sangat rentan untuk terjangkit penyakit terurama infeksi karena daya tahan tubuh bayi belum terbentuk dan berfungsi secara optimal upaya yang dapat dilakukan untuk mencegah hal tersebut adalah dengan melakukan imunisasi merupakan usaha memberikan kekebalan tubuh pada bayi dan anak dengan memasukkan vaksin kedalam tubuh untuk mencegah penyakit. Namun dalam melakukan prosedur imunisasi kerap sekali menimbulkan rasa nyeri pada bayi terutama saat melakukan prosedur injeksi sehingga sering disebut sebagai salah satu sumber nyeri akut pada bayi [1]. Nyeri yang dialami bayi saat imunisasi disebabkan akibat rendahnya kadar endorphine pada bayi. Oleh sebab itu, perawat perlu mempertimbangkan bagaimana meminimalkan ketidak nyamanan dan nyeri yang dirasakan oleh bayi tujuan untuk mengetahui Pengaruh pemberian metode 5'S (Swaddling, Stomach Position, Sushing, Swinging, Sucking) dari sebelum dan sesudah diberikan terhadap respon nyeri pada bayi setelah Imunisasi Hb-0.

\section{Metode}

Jenis penelitian ini merupakan penelitian kuantitatif. Penelitian ini menggunakan desain penelitian Quasy Experiment (eksperiment semu) dengan rancangan one grup pretest post test, karena penelitian ini diarahkan untuk melihat bagaimana pengaruh metode 5'S (Swaddling, Stomach Position, Swinging, Sushing dan Sucking) terhadap respon nyeri pada bayi setelah imunisasi Hb-0. Instrumen dalam penelitian ini adalah lembar observasi skala pengukuran nyeri 
NIPS (Neonatal Infant Pain Scale) 0-8. Populasi dalam penelitian ini adalah bayi yang mendapat imunisasi Hb-0 di RS GrandMed Lubuk Pakam Kabupaten Deli serdang. Pengambilan sampel menggunakan metode purposive sampling yaitu cara memilih sampel diantara populasi sesuai dengan kriteria inklusi sampel yang ditentukan dengan jumlah sample sebanyak 40 orang bayi dan hasil di analisa dengan menggunakan uji $t$ dengan tingkat kepercayaan $95 \%(P$ value $\leq 0.05)[2]$. Hipotesa merupakan jawaban sementara dari rumusan masalah atau jawaban penelitian. Hipotesa dalam penelitian ini adalah Ada pengaruhmetode 5'S (Swaddling, stomach Position, Sushing, Swinging, and Sucking) Terhadap Respon Nyeri Pada Bayi Setelah Imunisasi Hb-0 di Rumah Sakit Grandmed Lubuk Pakam

\section{Hasil dan Diskusi}

Penelitian tentang Pengaruh Metode 5'S (Swaddling, Side/Stomach Position, Sushing, Swinging dan Sucking) Terhadap Respon Nyeri Pada Bayi Setelah Melakukan Imunisasi Hb-0 Tahun 2020 dilakukan mulai 12 April 2020 sampai 20 Mei 2020 di Rumah Sakit Grandmed Lubuk Pakam Kabupaten Deli Serdang. Sampel dalam penelitian ini sebanyak 40 orang penelitian ini menggunakan desain penelitian Quasy Experiment (eksperiment semu) dengan rancangan one grup pretest post test tehnik metode purposive sampling yaitu cara memilih sampel diantara populasi sesuai dengan kriteria inklusi sampel yang ditentukan dengan jumlah sample sebanyak 40 orang bayi dan hasil di analisa dengan menggunakan uji $t$ dengan tingkat kepercayaan $95 \%$.

\begin{tabular}{cccc}
\multicolumn{5}{c}{ Tabel 1. Distribusi Responden Berdasarkan Karakteristik Usia pada } \\
Bayi & yang Mendapatkan Imunisasi Hb-0 & \\
\hline No & $\begin{array}{c}\text { Usia Responden } \\
\text { ( hari ) }\end{array}$ & $\begin{array}{c}\text { Frekuensi } \\
\text { (orang) }\end{array}$ & Persentase (\%) \\
\hline 1 & 0 & 7 & $17.5 \%$ \\
2 & 1 & 12 & $30 \%$ \\
3 & 2 & 6 & $15 \%$ \\
4 & 3 & 5 & $12.5 \%$ \\
5 & 4 & 4 & $10 \%$ \\
6 & 5 & 3 & $7.5 \%$ \\
7 & 6 & 2 & $5 \%$ \\
\hline
\end{tabular}

Berdasarkan tabel 1 dapat diketahui bahwa jumlah responden yaitu usia 0 hari sebanyak 7 orang $(17,5 \%)$, jumlah responden berusia 1 hari sebanyak 12 orang $(30,0 \%)$, jumlah responden berusia 2 hari sebanyak 6 orang $(15,0 \%)$, jumlah responden berusia 3 hari sebanyak 5 orang $(12,5$ $\%)$, jumlah responden berusia 4 hari sebanyak 4 orang $(10,0 \%)$, responden berusia 5 hari sebanyak 3 orang $(7,5 \%)$, responden berusia 6 hari sebanyak 2 orang $(5,0 \%)$, responden berusia 7 hari sebanyak 1 orang $(2,5 \%)$ dengan total responden sebanyak 40 orang $(100 \%)$.

Penelitian ini sejalan dengan penelitian sebelumnya didapatkan bahwa bayi yang mendapatkan imunisasi terbanyak yaitu usia 0 sampai 3 hari sebanyak 13 orang (52\%). Rata-rata skala nyeri pada neonatus kelompok perlakuan adalah 7,80 dan pada kelompok konterol 11,20. Hasil penelitian yang dilakukan menunjukkan adanya perbedaan yang signifikan durasi tangisan neonatus kelompok perlakuan dan kelompok kontrol dengan $p=0,011$. Dan dapat disimpulkan bahwa ada pengaruh tindakan 5's terhadap skala nyeri neonatus yang ditunjukkan dengan uji statistik t-test dengan $p=0,0000$, yang ditunjukkan dengan uji statistik t-test dengan $p=0,011$ [1]. 
Metode 5'S (Swaddling, Side/Stomach Position, Sushing, Swinging, dan Sucking) Tabel 1. Skala Nyeri Pre Test Swaddling

\begin{tabular}{llcc}
\hline \multicolumn{3}{c}{ Pre Test Swaddling } \\
\hline No & Skala Nyeri & Frekuensi & Persentase (\%) \\
\hline 1 & Nyeri Ringan (1-3) & 8 & $20 \%$ \\
2 & Nyeri Sedang (4-6) & 9 & $22.5 \%$ \\
3 & Nyeri Berat (7-8) & 23 & $57.5 \%$ \\
\hline & Total & $\mathbf{4 0}$ & $\mathbf{1 0 0 \%}$ \\
\hline
\end{tabular}

Berdasarkan tabel 1 didapatkan bahwa Skala Nyeri Pre Test Swaddling yaitu nyeri ringan (1-3) sebanyak 8 orang (20\%), skala nyeri sedang (4-6) sebanyak 9 orang (22,5\%), nyeri berat ((78) sebanyak 23 Orang $(57,5 \%)$.

Tabel.2 Skala Nyeri Post Test Swaddling

\begin{tabular}{cccc}
\hline \multicolumn{3}{c}{ Post Test Swadding } \\
\hline No & Skala Nyeri & Frekuensi & Persentase \% \\
\hline 1 & Tidak nyeri (0) & 6 & $15 \%$ \\
2 & Nyeri Ringan (1-3) & 28 & $70 \%$ \\
3 & Nyeri Sedang (4-6) & 6 & $15 \%$ \\
\hline & Total & $\mathbf{4 0}$ & $\mathbf{1 0 0 \%}$
\end{tabular}

Berdasarkan tabel 2 didapatkan bahwa Skala Nyeri Post Test Swaddling yaitu tidak nyeri (0) sebanyak 6 orang (15\%), skala nyeri ringan (1-3) sebanyak 28 orang (70\%), dan skala nyeri sedang (4-6) sebanyak 6 orang (15\%).

Tabel 3. Skala Nyeri Pre Test Side/stomach Position

\begin{tabular}{llcc}
\hline \multicolumn{3}{c}{ Pre Test Side Stomach Position } \\
\hline No & Skala Nyeri & Frekuensi & Persentase \\
\hline 1 & Tidak nyeri (0) & 8 & $20 \%$ \\
2 & Nyeri Ringan (1-3) & 12 & $30 \%$ \\
3 & Nyeri Sedang (4-6) & 18 & $45 \%$ \\
4 & Nyeri Berat (7-8) & 2 & $5 \%$ \\
\hline & Total & $\mathbf{4 0}$ & $\mathbf{1 0 0} \%$
\end{tabular}

Berdasarkan tabel 3 didapatkan bahwa Pre test Side_Stomach Position tidak nyeri (0) sebanyak 8 orang (20\%), nyeri ringan (1-3) sebanyak 12 orang (30\%), skala nyeri sedang (4-6) sebanyak 18 orang (45\%), dan nyeri berat (7-8) sebanyak 2 orang $(5 \%)$.

Tabel .4 Skala Nyeri Post Test Side/Stomach Position

\begin{tabular}{|c|c|c|c|}
\hline \multicolumn{4}{|c|}{ Post Test Side/ StomachPosition } \\
\hline No & Skala Nyeri & Frekuensi & Persentase (\%) \\
\hline 1 & Tidak nyeri (0) & 21 & $52.5 \%$ \\
\hline 2 & Nyeri Ringan (1-3) & 18 & $45 \%$ \\
\hline 3 & Nyeri Sedang (4-6) & 1 & $2.5 \%$ \\
\hline & Total & 40 & $100 \%$ \\
\hline
\end{tabular}

Berdasarkan tabel 4 didapatkan bahwa skala nyeri post test Side/ Stomach Position yaitu tidak nyeri (0) sebanyak 21 orang (52,5\%), nyeri ringan (1-3) sebanyak 18 orang (45\%), dan skala nyeri sedang (4-6) sebanyak 1 orang $(2,5 \%)$. 
Tabel 5. Skala Nyeri Pre Test Sushing dan Swinging Pre Test Shushing, dan Swingging

\begin{tabular}{cccc}
\hline No & Skala Nyeri & Frekuensi & Persentase (\%) \\
\hline 1 & Tidak nyeri (0) & 5 & $12.5 \%$ \\
2 & Nyeri Ringan (1-3) & 8 & $20 \%$ \\
3 & Nyeri Sedang (4-6) & 21 & 52.5 \\
4 & Nyeri Berat (7-8) & 6 & $15 \%$ \\
\hline & Total & $\mathbf{4 0}$ & $\mathbf{1 0 0 \%}$ \\
\hline
\end{tabular}

Berdasarkan tabel 5 didapatkan bahwa Pre_Test Shushing, dan Swinggingyaitu tidak nyeri (0) sebanyak 5 orang (12,5\%), nyeri ringan (1-3) seanyak 8 orang (20\%), nyeri sedang (4-6) sebanyak 21 orang $(52,5 \%)$, dan skla nyeri berat $(7-8)$ sebanyak 6 orang $(15 \%)$.

Tabel 6. Tabel Post Test Sushing dan Swinging

\begin{tabular}{|c|c|c|c|}
\hline \multicolumn{4}{|c|}{ Post Test Shushing dan Swingging } \\
\hline No & Skala Nyeri & Frekuensi & Persentase (\%) \\
\hline 1 & Tidak nyeri (0) & 13 & $32.5 \%$ \\
\hline 2 & Nyeri Ringan (1-3) & 23 & $57.5 \%$ \\
\hline 3 & Nyeri Sedang (4-6) & 4 & $10 \%$ \\
\hline & Total & 40 & $100 \%$ \\
\hline
\end{tabular}

Berdasarkan tabel 6 didapatkan bahwa Skala Nyeri Post Test SwinggingShushing tidak nyeri (0) sebanyak 13 orang (32,5\%), nyeri ringan (1-3) sebanyak 23 orang (57,5\%), dan skala nyeri sedang (4-6) sebanyak 4 orang (10\%).

Tabel 7. Skala Nyeri Pre Test Sucking

\begin{tabular}{cccc}
\hline \multicolumn{4}{c}{ Pre Test Sucking } \\
\hline No & Skala Nyeri & Frekuensi & Persentase (\%) \\
\hline 1 & Tidak nyeri (0) & 3 & $7.5 \%$ \\
2 & Nyeri Ringan (1-3) & 5 & $12.5 \%$ \\
3 & Nyeri Sedang (4-6) & 7 & $17.5 \%$ \\
4 & Nyeri Berat (7-8) & 25 & $62.5 \%$ \\
\hline & Total & $\mathbf{4 0}$ & $\mathbf{1 0 0} \%$ \\
\hline
\end{tabular}

Berdasarkan tabel 7 didapatkan bahwa Pre Test Sucking yaitu tidak nyeri (0) sebanyak 3 orang $(7,5 \%)$, nyeri ringan (1-3) sebanyak 5 orang (12,5\%), nyeri sedang (4-6) sebanyak 7 orang $(17,5 \%)$, dan nyeri berat (7-8) sebanyak 25 orang $(62,5 \%)$.

Tabel 8. Skala Nyeri Post Test Sucking

\begin{tabular}{cccc}
\hline \multicolumn{4}{c}{ Post Test Sucking } \\
\hline No & Skala Nyeri & Frekuensi & Persentase (\%) \\
\hline 1 & Tidak nyeri (0) & 7 & $17.5 \%$ \\
\hline 2 & Nyeri Ringan (1-3) & 25 & $62.5 \%$ \\
\hline 3 & Nyeri Sedang (4-6) & 7 & $17.5 \%$ \\
\hline 4 & Nyeri Berat (7-8) & 1 & $2.5 \%$ \\
\hline & Total & $\mathbf{4 0}$ & $\mathbf{1 0 0} \%$
\end{tabular}


Berdasarkan tabel 8 didapatkan bahwa Skala Nyeri Post Test Sucking yaitu tidak nyeri (0) sebanyak 7 orang (17,5), nyeri ringan (1-3) sebanyak 25 orang $(62,5)$, nyeri sedang (4-6) sebanyak 7 orang $(17,5 \%)$,dan nyeri berat (7-8) sebanyak 1 Orang $(2,5 \%)$.

Perawat perlu mempertimbangkan bagaimana meminimalkan ketidak nyamanan dan nyeri yang dirasakan oleh bayi. Namun saat menerapkan metode 5'S, Lee menemukan hal yang mengejutkan karena bayi yang awalnya menangis perlahan diam dan saturasi oksigen yang awalnya menurun kembali normal dan Heart Rate bayi yang awalnya meningkat perlahan kembali normal. bayi yang mendapatkan intervensi metode 5'S berhenti menangis dengan 45 detik, sedangkan yang menerima larutan gula masih menangis dalam 2 menit setelah invasif vaksinasi. Hal ini dikarenakan bayi memerlukan kenyamanan [3].

Tindakan yang bisa dilakukan untuk mengelola nyeri secara non farmakologis untuk mengurangi nyeri saat imunisasi adalah menggunakan intervensi Metode 5'S. Tindakan 5'S ini merupakan salah satu upaya yang bisa dilakukan untuk memberikan kenyamanan pada bayi mengkondisikan ulang seperti dalam kandungan " agar bayi tenang dan nyaman, dengan metode 5's yang meliputi swaddling (membedong bayi), side/stomach position (posisi miring kekiri/ perut), shushing sound (memberikan suara sshhhh), swinging (gerakan mengayun), sucking (menghisap/memberikan ASI). Teknik tersebut dilakukan karena dalam 3 bulan pertama setelah kelahirannya, bayi merindukan sensasi-sensasi nyaman yang mereka alami selama berada dalam rahim ibu [4].

\section{Analisa Bivariat}

Analisa Bivariat digunakan untuk menjelaskan atau mengetahui adanya pengaruh yang signifikan antara variabel independen dan variabel dependen. Dengan menggunakan teknik analisa data Paired Sample t testdengan derajat kemaknaan yaitu $\mathrm{a}=0,05$. Hasil analisa data bivariat adalah sebagai berikut :

\section{A. Pengaruh Metode 5'S Terhadap Respon Nyeri Pada Bayi Setelah Imunisasi Hb-0 1. Pengaruh Metode Swaddling Terhadap Respon Nyeri Bayi}

\begin{tabular}{llccc}
\hline & & N & Correlation & Sig. \\
\hline Pair 1 & $\begin{array}{l}\text { Pre Test Swaddling } \\
\text { Post Test Swadding }\end{array}$ & 40 & .516 & .001 \\
\hline & Berdasarkan tabel di atas didapatkan & bahwa & nilai & signifikan \\
\hline
\end{tabular}
Swaddling $=0,001(\mathrm{a}<0,05)$ yang artinya ada pengaruh sebelum dan sesudah dilakukan perlakuan swaddling.

\section{Pengaruh Metode Side/Stomach Position Terhadap Respon Nyeri Bayi}

\begin{tabular}{llccc}
\hline & N & Correlation & Sig. \\
\hline Pair 1 & $\begin{array}{l}\text { Pre test Side/ stomach Position } \\
\text { PostTest Side/Stomach Position }\end{array}$ & 40 & .696 & .000 \\
\hline
\end{tabular}

Berdasarkan tabel di atas didapatkan bahwa nilai signifikan pre test dan post test Side/Stomach Position= 0,000 $(\mathrm{a}<0,05)$ yang artinya ada pengaruh sebelum dan sesudah dilakukan perlakuan Side/Stomach Position.

\section{Pengaruh Metode Sushing dan Swinging Terhadap Respon Nyeri Bayi}

\begin{tabular}{|c|c|c|c|c|}
\hline & & $\mathbf{N}$ & Correlation & Sig. \\
\hline Pair 1 & $\begin{array}{l}\text { Pre TestSushing dan } \\
\text { Swingging } \\
\text { Post Test Sushing dan } \\
\text { swinging }\end{array}$ & 40 & .905 & .000 \\
\hline
\end{tabular}




\section{Pengaruh Metode Sucking Terhadap Respon Nyeri Bayi}

\begin{tabular}{lllcc}
\hline & N & Correlation & Sig. \\
\hline Pair 1 & $\begin{array}{l}\text { Pre Test Sucking } \\
\text { Post Test Sucking }\end{array}$ & 40 & .710 & .000 \\
\hline & Berdasarkan tabel 4 didapatkan bahwa nilai signifikan pre test dan post test Sucking=0,000
\end{tabular}

Berdasarkan tabel 4 didapatkan bahwa nilai signifikan pre test dan post test Sucking $=0,000$ $(a<0,05)$ yang artinya ada pengaruh sebelum dan sesudah dilakukan perlakuan Sucking. Berdasarkan hasil analisa data dengan menggunakan uji paired sample $t$ testdiperoleh nilai $\mathrm{p}$ $(0,005)<a(0,05)$, yang artinya Hipotesa Alternatif diterima yang berarti ada pengaruh Metode 5'S (Swaddling, Side/Stomach Position, Sushing, Swinging dan Sucking) Terhadap Respon Nyeri pada bayi Setelah Imunisasi Hb-0 di Rumah Sakit Grandmed Lubuk Pakam.

Penelitian sebelumnya yang dilakukan oleh Trimawati juga memberikan asumsi bahwa berdasarkan uji statistik yang dilakukan didapatkan bahwa total 80 responden yang terlibat dalam penelitian yang terbagi atas $41(51,2 \%)$ responden dalam kelompok intervensi dan $39(48,8 \%)$ dalam kelompok kontrol. Distribusi respon nyeri imunisasi didapatkan nyeri berat banyak ditemukan dalam kelompok kontrol. Selanjutnya setelah dilakukan analisis uji Chi Squaredidapatkan bahwa nilai $\mathrm{p}$ dari semua pengukuran nyeri yang dilakukan saat penyuntikan imunisasi yang diukur dengan menggunakan skala nyeri MBPS adalah $\mathrm{p}<0,05$ yang artinya ada hubungan metode 5'S terhadap skala nyeri pada bayi saat imunisasi [5].

Hasil penelitian ini didukung dengan adanya asumsi penelitian sebelumnya yang menyimpulkan bahwa 20 responden yang terdiri dari 2 kelompok yaitu kelompok perlakuan dan kelompok kontrol dan didapatkan hasil bahwa nyeri pada kelompok kontrol rata-rata mengalami nyeri hebat dengan skor 13 dan nyeri terendah yaitu dengan skor 9. Sedangkan pada kelompok perlakuan rata-rata bayi mengalami nyeri ringan dengan skor 9 hingga nyeri sedang debgan skor 7$12[6]$.

\section{Pembahasan}

\subsection{Karakteristik Responden Berdasarkan Karakteristik Usia pada Bayi yang \\ Mendapatkan Imunisasi Hb-0 di Rumah Sakit Grandmed Lubuk Pakam}

Berdasarkan analisa data yang dilakukan dalam penelitian ini asumsi peneli yaitu diketahui bahwa jumlah responden yaitu usia 0 hari sebanyak 7 orang $(17,5 \%)$, jumlah responden berusia 1 hari sebanyak 12 orang $(30,0 \%)$, jumlah responden berusia 2 hari sebanyak 6 orang $(15,0 \%)$, jumlah responden berusia 3 hari sebanyak 5 orang $(12,5 \%)$, jumlah responden berusia 4 hari sebanyak 4 orang $(10,0 \%)$, responden berusia 5 hari sebanyak 3 orang $(7,5 \%)$, responden berusia 6 hari sebanyak 2 orang $(5,0 \%)$, responden berusia 7 hari sebanyak 1 orang $(2,5 \%)$ dengan total responden sebanyak 40 orang $(100 \%)$. Berdasarkan analisa data yang dilakukan didapatkan bahwa mayoritas usia responden yag mendapatkan imunisasi dengan jumlah terbanyak yaitu responden dengan usia 2 hari dengan respon nyeri yang berbeda.

Penelitian ini sejalan dengan penelitian sebelumnya didapatkan bahwa bayi yang mendapatkan imunisasi terbanyak yaitu usia 0 sampai 3 hari sebanyak 13 orang (52\%). Rata-rata skala nyeri pada neonatus kelompok perlakuan adalah 7,80 dan pada kelompok konterol 11,20. Hasil penelitian yang dilakukan menunjukkan adanya perbedaan yang signifikan durasi tangisan neonatus kelompok perlakuan dan kelompok kontrol dengan $\mathrm{p}=0,011$. Dan dapat disimpulkan bahwa ada pengaruh tindakan 5's terhadap skala nyeri neonatus yang ditunjukkan dengan uju statistic t-test dengan $p=0,0000$, yang ditunjukkan dengan uji statistik t-test dengan $p=0,011$ [7]

Penelitian sebelumnya yang dilakukan oleh Trimawati juga memberikan asumsi bahwa berdasarkan uji statistik yang dilakukan didapatkan bahwa total 80 responden yang terlibat dalam penelitian yang terbagi atas $41(51,2 \%)$ responden dalam kelompok intervensi dan $39(48,8 \%)$ dalam kelompok kontrol. Distribusi respon nyeri imunisasi didapatkan nyeri berat banyak ditemukan dalam kelompok kontrol. Selanjutnya setelah dilakukan analisis uji Chi Squaredidapatkan bahwa nilai $\mathrm{p}$ dari semua pengukuran nyeri yang dilakukan saat penyuntikan imunisasi yang diukur dengan menggunakan skala nyeri MBPS adalah $\mathrm{p}<0,05$ yang artinya ada hubungan metode 5'S terhadap skala nyeri pada bayi saat imunisasi [8]. 


\subsection{Metode 5'S (Swaddling, Side/Stomach Position, Swinging, Sushing dan Sucking)}

Berdasarkan penelitian yang dilakukan asumsi penelitu yaitu Skala Nyeri Pre Test Swaddling mayoritas yaitu nyeri berat (7-8) sebanyak 23 Orang (57,5\%), namun setelah diberikan perlakuan Post Test Swaddlingskala nyeri mayoritas berubah menjadi yaitu skala nyeri ringan (1-3) sebanyak 28 orang (70\%).Skala Nyeri Pre test Side Stomach Position mayoritas skala nyeri sedang (4-6) sebanyak 18 orang (45\%), namun setelah diberika perlakuan Side/ Stomach Positionskala nyeri mayoritas berubah menjadi nyeri ringan (1-3) sebanyak 18 orang (45\%). Skala Nyeri Pre_Test Swingging, Shushingmayoritas yaitu skala nyeri sedang (4-6) sebanyak 21 orang (52,5\%), namun setelah diberikan perlakuan Swinging dan Shushingskala nyeri mayoritas berubah menjadinyeri ringan (1-3) sebanyak 23 orang (57,5\%). Skala Nyeri Pre Test Sucking mayoritas yaitu nyeri berat (7-8) sebanyak 25 orang $(62,5 \%)$, namun setelah diberikan perlakuan Sucking skala nyeri mayoritas berubah menjadi nyeri ringan (1-3) sebanyak 25 orang $(62,5 \%)$ [9].

Dari hasil penelitian yang dilakukan juga, peneliti dapat menyampaikan asumsi bahwa metode 5'S efektif untuk mengurangi respon nyeri pada bayi yang ditandai dengan perbandingan nyeri sebelum dan sesudah perlakuan yang sangat dapat dilihat pada tabel diatas. Sebelum dilakukan perlakuan mayoritas bayi mengelami respon nyeri sedang (4-6) dan berat (7-8) sedangkan setelah diberikan perlakuan respon nyeri ada bayi berkurang yang ditandai dengan mayoritas bayi mengalami nyeri ringan (1-3) dan tidak ada nyeri (0).

Hasil penelitian ini didukung dengan adanya asumsi penelitian sebelumnya yang menyimpulkan bahwa 20 responden yang terdiri dari 2 kelompok yaitu kelompok perlakuan dan kelompok kontrol dan didapatkan hasil bahwa nyeri pada kelompok kontrol rata-rata mengalami nyeri hebat dengan skor 13 dan nyeri terendah yaitu dengan skor 9. Sedangkan pada kelompok perlakuan rata-rata bayi mengalami nyeri ringan dengan skor 9 hingga nyeri sedang debgan skor 7$12[10]$.

Hasil penelitian tersebut sejalan dengan asumsi peneliti sebelumnya yang menyimpulkan bahwa didapatkan nilai rerata nyeri pada kelompok Intervensi 5'S yaitu 7,80 dan pada kelompok kontrol 11,20. Hal ini menunjukkan bahwa skala nyeri pada kelompok perlakuan lebih rendah dibandingkan dengan kelompok kontrol [11].

\subsection{Pengaruh Metode 5'S Terhadap Respon Nyeri Pada Bayi Setelah Imunisasi Hb-0 Di Rumah Sakit Grandmed Lubuk Pakam}

Berdasarkan analisa data yang dilakukan dalam penelitian ini peneliti memberikan asumsi bahwa hasil analisa data dengan menggunakan uji paired sample t testdiperoleh nilai $\mathrm{p}(0,005)<\mathrm{a}$ $(0,05)$, yang artinya Hipotesa Alternatif diterima yang berarti ada pengaruh Metode 5'S (Swaddling, Side/Stomach Position, Sushing, Swinging dan Sucking) Terhadap Respon Nyeri pada bayi Setelah Imunisasi Hb-0 di Rumah Sakit Grandmed Lubuk Pakam [12].

Penelitian ini sejalan dengan penelitian sebelumnya yang dilakukan oleh Setiyorini yang memberikan asumsi bahwa ada pengaruh pemberian metode 5'S terhadap skala nyeri neonatus yang ditunjukkan dengan uji statistik t-test dengan $\mathrm{p}=0,000$, adanya pengaruh pemberian metode 5'S terhadap skala nyeri neonatus yang ditunjukkan dengan uji statistik t-test $\mathrm{p}=0,011$ $(\mathrm{p}<0,05)[13]$. Asumsi peneliti sebelumnya juga menyatakan bahwa berdasarakan analisa data yang didapatkan, bayi kerap mengalami respon nyeri yang tidak stabil khususnya apabila bayi mendapatkan tindakan infasif, hal ini dikarenakan pada bayi yang baru lahir hingga usia 3 bulan memerlukan adaptasi dengan lingkungan luar yang berbeda dengan suasana dalam rahim dan bayi memerlukan kenyamanan untuk beradaptasi dalam upaya penyesuaian diri terhadap lingkungan luar rahim [14].

Berdasarkan hasil analisa dengan menggunakan uji paired sampel t test diperoleh nilai $\mathrm{p}$ $(0,005)<\mathrm{a}(0,05)$, yang artinya Hipotesa alternatif diterima yang berarti ada pengaruh Metode 5'S (Swaddling, Side/Stomach Position, Swinging, Sushing dan Sucking) Terhadap Respon Nyeri pada bayi Setelah Imunisasi hb-0 di Rumah Sakit Grandmed Lubuk Pakam [15]. 


\section{Kesimpulan}

Berdasarkan hasil analisa data dengan menggunakan uji paired sample t testdiperoleh nilai $\mathrm{p}$ $(0,005)<\mathrm{a}(0,05)$, yang artinya Hipotesa Alternatif diterima yang berarti ada pengaruh Metode 5'S (Swaddling, Side/Stomach Position, Sushing, Swinging dan Sucking) Terhadap Respon Nyeri pada bayi Setelah Imunisasi Hb-0 di Rumah Sakit Grandmed Lubuk Pakam dan diharapkan penelitian ini dapat memberikan informasi kepada Responden tentang Pengaruh pemberian metode 5's (Swaddling, Side/Stomach Position, Sushing, Swinging, Sucking) terhadap respon nyeri pada bayi setelah Imunisasi Hb-0 di Rumah Sakit Grandmed Lubuk Pakam.

\section{Ucapan Terima Kasih}

Terima kasih kepada Kementerian Pendidikan dan Kebudayaan (KEMENDIKBUD) dan kepada Lembaga Layanan Pendidikan Tinggi Wilayah I (LLDIKTI) serta Rumah sakit Grandmed Lubuk Pakam. Dengan adanya bantuan dari semua pihak, penelitian ini dapat berlangsung dengan baik semoga hasil penelitian ini dapat bermanfaat untuk masyarakat khususnya ibu yang mempunyai Bayi yang akan diimunisasi.

\section{Referensi}

[1] Trimawati. (2016). Efektivitas Metode 5'S ( Swaddling, Side/Stomach Position, Swinging, Sushing dan Sucking) Terhadap Respon Nyeri Pada Bayi Saat Imunisasi Pentavelen. Semarang: Jurnal Keperawatan Anak, Volume 3, No.1.

[2] Sastroasmoro, S. (2017). Dasar-Dasar Metodologi Penelitian Klinis Edisi 5. Jakarta: Sagung Seto.

[3] Judha Muhamad, Sudarti, Fauziah Afroh. (2015). Teori Pengukuran Nyeri dan Nyeri Persalinan. Yogyakarta: Nuha Medika.

[4] Juraida Roito, Noor Nurmailis, Mardiah. (2013). Asuhan Ibu Nifas dan Deteksi Dini Komplikasi. Jakarta: EGC.

[5] Trimawati. (2016). Efektivitas Metode 5'S ( Swaddling, Side/Stomach Position, Swinging, Sushing dan Sucking) Terhadap Respon Nyeri Pada Bayi Saat Imunisasi Pentavelen. Semarang: Jurnal Keperawatan Anak, Volume 3, No.1.

[6] Mulyani Siti, R. (2018). Imuniasi Untuk Anak. Yogyakarta: Nuha Medika.

[7] Setiyorini Erni, Wulandari Arti Ning. (2014). Aplikasi Teknik Swaddling, Side-Stomach, Sushing, Swinging, Sucking (5’S) Terhadap Skala Nyeri dan Durasi Tangisan Pada Neonatus Paska Prosedur Pengambilan Darah. Blitar: Jurnal Ners dan Kebidanan.

[8] Juraida Roito, Noor Nurmailis, Mardiah. (2013). Asuhan Ibu Nifas dan Deteksi Dini Komplikasi. Jakarta: EGC.

[9] Wahyuni, Sari. (2018). Asuhan Neonatus, Bayi, dan Balita. Jakarta: EGC.

[10] Mulyani Siti, Rinawati. (2018). Imuniasi Untuk Anak. Yogyakarta: Nuha Medika.

[11] Harrington. (2012). Aplikasi Teknik Swaddling, Side-Stomach, Sushing, Swinging, Sucking (5 'S) Terhadap Skala Nyeri dan Durasi Tangisan Pada Neonatus Paska Prosedur Pengambilan Darah. Blitar: Jurnal Ners dan Kebidanan.

[12] Rudolph. (2015). Imunisasi Pada Neonatus Jurnal. Semarang.

[13] Hidayat. (2013). Pengaruh Bola Bobath Terhadap Skor Nyeri Pada Bayi Usia 9-12 Bulan Saat Imunisasi Di Puskesmas Ciputat Timur Tangerang Selatan Jurnal. Tangerang.

[14] Kemenkes. (2013). Buku Ajar Imunisasi. Jakarta: Pusat Pendidikan dan Pelatihan Tenaga Kesehatan

[15] Azari Muhammad, Safri, Woferst. (2015). Gambaran Skala Nyeri Pada Anak Dengan Menggunakan Skala Nyeri FLACC Scale Saat Tindakan Invasif Jurnal. Riau. 